\section{Conditioned fear training and later avoldance learning in the goldfish ${ }^{1}$}

KENNETH FRUMKIN and KENNETH $H$. BROOKSHIRE, Franklin and Marshall College, Lancaster, Pa. 17604

In Experiment 1 goldfish showed early facilitation of one-way avoidance behavior following conditioned fear training. In a second experiment, two-way avoidance behavior was studied. An interference effect emerged but only under conditions suggesting a fatigue explanation.

It has been reported that Pavlovian fear conditioning can facilitate (Brookshire \& Frumkin, 1969) or interfere with (Pinckney, 1967) subsequent acquisition of a conditioned avoidance response (CAR) in fish. The purpose of the present work was to isolate some of the conditions under which such facilitation or interference might occur.

\section{EXPERIMENT 1}

Baum (1969) and Brookshire \& Hognander (1968) have suggested that facilitation of avoidance learning following conditioned fear training may occur more readily when task difficulty is minimized. The reasoning is that during Pavlovian fear conditioning two events may be occurring: the acquisition of conditioned fear and the acquisition of competing responses. It can be argued that in less difficult avoidance tasks, in which the required CAR is more readily available to the $S$ (i.e., prepotent in relation to acquired competing responses), conditioned fear could permit early potentiation of the CAR and, therefore, yield a facilitation effect.

It has been shown that a one-way avoidance problem is less difficult than a two-way (shuttle) avoidance problem for rats (Theios \& Dunaway, 1964) and for fish. ${ }^{2}$ Moreover, since de Toledo \& Black (1967) have found facilitation of one-way avoidance learning in rats by conditioned fear, it was hypothesized that Pavlovian fear conditioning would facilitate one-way avoidance learning in fish.

\section{Method}

The Ss were 16 goldfish /Carassius auratus/ averaging 2-3 in. in length, obtained from a local supplier and housed initially in a communal tank. During the experiment each $S$ was kept in a separate compartment of a larger tank.

The essential features of the apparatus have been described elsewhere (Brookshire \& Frumkin, 1969). Briefly, it was a two-compartment aquatic shuttlebox, painted gray on one side and white on the CS or US.

\section{Results} for the total 40 trials.

\section{EXPERIMENT 2}

Table 1

Mean Percentage Of Avoidances in Experiment 1

\begin{tabular}{lcc}
\hline & \multicolumn{2}{c}{ Trials } \\
\cline { 2 - 3 } Experimental Group & 42.5 & $1-40$ \\
Control Group & 15.0 & 71.6 \\
\hline
\end{tabular}

other. A 6-V light served as a CS, and a pulsed, 12-V shock served as the US.

The Ss were divided into experimental and control groups $(\mathrm{N}=8)$. After a 7 -min adaptation period, experimental $S$ s received 20 Pavlovian fear-conditioning trials (ITI = $2 \mathrm{~min}$ ) per day for a 2 -day period. A delayed conditioning procedure was used with a 10-sec CS-US interval. Duration of the US was $5 \mathrm{sec}$. Control Ss were placed in the gray compartment for $50 \mathrm{~min}$ on each of the 2 days without experiencing either the

Avoidance testing was begun on the third day and continued, 10 trials per day, for 4 consecutive days. A trial began with the presentation of the CS simultaneously with the lifting of a guillotine door between the two compartments. Interception of photocell beams separating the two compartments terminated either the CS (avoidance) or CS and US (escape). If no response was made in 2 min the trial was terminated by $\mathrm{E}$. As during fear conditioning, the CS-US interval was $10 \mathrm{sec}$ and the ITI was $2 \mathrm{~min}$. All $\mathrm{Ss}$ were trained to swim from the gray compartment to the white compartment. The $S$ was returned to the gray side $105 \mathrm{sec}$ after completion of each response.

The mean percentage of avoidances for experimental and control groups is pre. sented in Table 1. For Trials 1-5, experimental Ss made significantly more avoidances than the control group $(t=2.54, \mathrm{df}=14$, $\mathrm{p}<.05)$. However, a reliable difference was not obtained for any other five-trial block or

Experiment 1 showed that Pavlovian fear conditioning produces early facilitation of CAR performance in fish in a one-way task. Since Pinckney (1967) found an increasing interference effect for two-way shuttle avoidance with an increasing number of prior fear-conditioning trials, it is tempting to account for the results by appealing to the variable of task difficulty. However, Brookshire \& Frumkin (1969) have failed to find interference effects of fear conditioning in a situation similar to Pinckney's. Two aspects of Pinckney's procedure and analysis differ markedly from that of Brookshire and Frumkin: First, Pinckney presented his Ss with the shuttlebox avoidance problem immediately following Pavlovian fear conditioning (rather than $24 \mathrm{~h}$ later); and second, Pinckney found a statistically significant interference effect only for Ss termed "poor performers" on the basis of a median split applied to each group. Thus, it remains possible that the interference effect, as distinguished from the lack of effect found with a similar group by Brookshire and Frumkin, is not a product of fear conditioning alone (e.g., competing responses). Instead, it may be the result of a combination of competing responses plus fatigue or debilitation produced by testing the Ss for 40 consecutive avoidance trials immediately after they had experienced a massed set of aversive stimuli. This is not unreasonable in view of the fact that Ss in one of Pinckney's experimental groups had spent over 4 consecutive hours in the apparatus, at least $2 \mathrm{~h}$ of which involved receiving a 5 -sec US every $3 \mathrm{~min}$. Furthermore, if debilitation or fatigue were operating in the Pinckney experiment, it is likely that this would tend to produce a decrement in the instrumental behavior of Ss with the least well established CARs, viz, the "poor performers." For these reasons it seemed advisable to investigate avoidance behavior both immediately and $24 \mathrm{~h}$ after Pavlovian fear conditioning. Debilitation or fatigue effects were assessed by comparing groups receiving CS-US pairings with groups receiving US (but not CS) presentations. Method

The Ss were 32 goldfish from the same stock and housed in the same manner as the Ss for Experiment 1.

The apparatus was an all-gray, twocompartment shuttlebox, similar to the one used in Experiment 1 and identical to that of Brookshire \& Frumkin (1969).

Two groups of eight Ss received 40 fearconditioning trials (10-sec CS-US interval, delayed conditioning, 5-sec US, ITI $=3 \mathrm{~min}$ ) in one side of the shuttlebox. Two other groups $(\mathrm{N}=8)$ were treated identically, except that they received the US alone. One fear-conditioned (CS-US) group and one US-only group were given 40 consecutive avoidance-training trials (same parameters as for the fear-conditioning trials) immediately after the completion of fear conditioning. The remaining two groups received an identical but "delayed" test $24 \mathrm{~h}$ later.

\section{Results}

Overall analysis of variance for number of avoidances yielded no significant differences among groups $(F<3.00$ for all sources, $\mathrm{df}=1 / 28, \mathrm{p}>.05)$. When the $\mathrm{Ss}$ in each group were divided by a median split into good and poor performers (after Pinckney, 


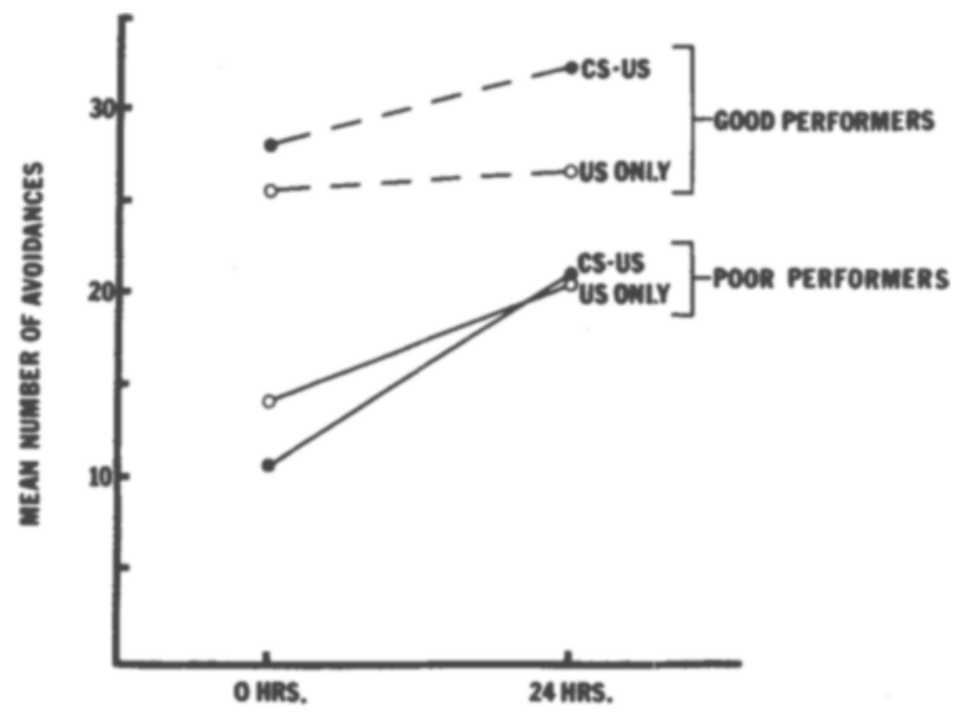

INTERVAL BETWEEN FEAR CONDITIONING AND TEST

1967), significant results emerged. For the good performers the number of avoidances in 40 trials for the CS-US groups was significantly greater than for Ss receiving US alone $(F=6.54, \mathrm{df}=1 / 12, \mathrm{p}<.05)$. For the poor performers, however, Ss tested immediately following fear conditioning made fewer avoidance responses than those for which avoidance training had been delayed $24 \mathrm{~h}(\mathrm{~F}=5.22, \mathrm{df}=1 / 12, \mathrm{p}<.05)$. No other sources were statistically significant for either analysis. Figure 1 shows the mean number of avoidances for good and poor performers as a function of treatment condition and the interval between treatment and test.

\section{DISCUSSION}

Experiment 1 showed that, in goldfish, there is a transient but reliable facilitatory effect of Pavlovian fear conditioning on subsequent one-way avoidance training. This confirms the results of de Toledo \& Black (1967) with rats and supports the hypothesis (Baum, 1969; Brookshire \& Hognander, 1968) that conditioned fear facilitation effects are more likely to be observed with avoidance tasks of minimum difficulty.

Some evidence for conditioned fear facilitation did emerge in Experiment 2 where (for good performers) groups receiving prior fear conditioning made more avoidances than those receiving experience with the US alone. More importantly, the data from the "poor performers" of Experiment 2 suggested that the interference effects of prior fear conditioning on avoidance behavior observed by Pinckney (1967, also in "poor performers") may not be due to competing responses alone, since groups which had experienced US only did not differ from those fish which had had CS-US pairings. Also, Ss tested immediately after the fear-conditioning phase of the experiment were markedly inferior to those Ss tested $24 \mathrm{~h}$ later. It seems reasonable to assume, then, that the interference phenomenon which Pinckney reported can be explained in terms of fatigue or shockinduced debilitation. This is not meant to imply that such nonassociational explanations can account for all reports of CAR interference following Pavlovian fear conditioning (cf. Weiss, Krieckhaus, \& Conte, 1968, with rats).

It is clear, however, that facilitation of avoidance responding by conditioned fear is more likely to occur in rats and fish when the task is a relatively easy one (Baum, 1969; de Toledo \& Black, 1967; cf. Experiment 1 ), and also when the required CAR is either prepotent (Rescorla, 1967; Weiss et al, 1968) or has more time in which to occur (Brookshire \& Frumkin, 1969). It is also apparent that interfering effects due to the presence of competing responses can mask

\section{ARTHUR STILL and ALASTAIR MACMILLAN, University of Durham, Durham, England}

Rats were given pairs of trials in two $T$ mazes, rotated at 90 deg with respect to each other, and they alternated turns at a rate significantly above chance, provided that part of the odor trail from Trial I was present on Trial 2. Contrary to the conclusion of Douglas (1966), alternation did not depend upon whether or not the rat could base its choice upon odor trail avoidance.
Fig. 1. Avoidance behavior of good and poor performers as a function of the interval between fear conditioning and test.

the facilitatory effects of conditioned fear and lead to no differences between fear and no-fear groups (Brookshire \& Frumkin, 1969; Experiment 2, overall analysis). Competing responses also may combine with fatigue to increase the degree of interference and lead to results such as those of Pinckney (1967).

\section{REFERENCES}

BAUM, M. Dissociation of respondent and operant processes in avoidance learning. Journal of Comparative \& Physiological Psychology, 1969. 67,83-88.

BROOKSHIRE, K. H., \& FRUMKIN, K. CS-US interval and conditioned fear facilitation of shuttlebox avoidance learning in the goldfish. Psychonomic Science, 1969, 3, 115-116.

BROOKSHIRE, K. H., \& HOGNANDER, O. C. Conditioned fear in the fish. Psychological Reports, 1968, 22, 75-81.

de TOLEDO, L., \& BLACK, A. H. Effects of preshock on subsequent avoidance conditioning. Journal of Comparative \& Physiological Psychology, 1967, 63, 493-499.

PINCKNEY, G. A. Avoidance learning in fish as a function of prior fear conditioning. Psychological Reports, 1967, 20, 71-74.

RESCORLA, R. A. Inhibition of delay and Pavlovian fear conditioning. Journal of Comparative \& Physiological Psychology, 1967, 64, 114120.

THEIOS, J., \& DUNAWAY, J. E. One-way versus shuttle avoidance learning- Psychonomic Science, 1964, 1, 251-252.

WEISS, J.M., KRIECKHAUS, E. E., \& CONTE, R. Effects of fear conditioning on subsequent avoidance behavior and movement. Journal of Comparative \& Physiological Psychology, 1968, $65,413-421$.

\section{NOTES}

1. This research was supported by Research Grant MH-05874 from the National Institute of Mental Health, USPHS. The authors are grateful for the contributions made to these studies by the following persons: Ira Fischler, David Kanofsky, Neil Novik, and George Strutt.

2. Brookshire, K. H. Unpublished data.

\section{Odor trail and spontaneous alternation}

Douglas (1966) apparently found that a sufficient condition for spontaneous alternation by rats in a T-maze was the presence of the animal's own odor trail leading down one arm. This was tested by giving rats successive trials in two identical mazes oriented at $90 \mathrm{deg}$ with respect to each other; if the same paper floor was used on the two trials, alternation (i.e., avoidance of odor trail) was about $65 \%$, while if the floor was changed it was at chance. Other tests by Douglas seemed to show that the only other basis for spontaneous alternation was a directional sense, and this could not possibly 